\title{
BMJ Open Burden and trend analysis of injury mortality in China among children aged 0-14 years from 2004 to 2011
}

\author{
Zhaoxue Yin, ${ }^{1}$ Jing Wu, ${ }^{1}$ Jiesi Luo, ${ }^{1}$ Anita WP Pak, ${ }^{2}$ Bernard CK Choi, ${ }^{3,4}$ \\ Xiaofeng Liang ${ }^{5}$
}

To cite: Yin Z, Wu J, Luo J, et al. Burden and trend analysis of injury mortality in China among children aged 0-14 years from 2004 to 2011. BMJ Open 2015;5: e007307. doi:10.1136/ bmjopen-2014-007307

- Prepublication history for this paper is available online. To view these files please visit the journal online (http://dx.doi.org/10.1136/ bmjopen-2014-007307).

Received 26 November 2014 Revised 15 May 2015 Accepted 19 May 2015

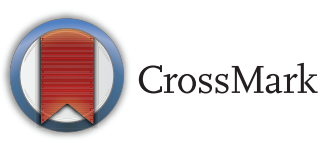

\footnotetext{
${ }^{1}$ Division of Noncommunicable Diseases Control and Community Health, Chinese Center for Disease Control and Prevention, Beijing, China ${ }^{2}$ Pak Consulting, Ottawa, Ontario, Canada

${ }^{3}$ Injury Prevention Research Center, Shantou University Medical College, Shantou, Guangdong, China

${ }^{4}$ Dalla Lana School of Public Health, University of Toronto, Toronto, Ontario, Canada ${ }^{5}$ Chinese Center for Disease Control and Prevention, Beijing, China
}

Correspondence to Jing $\mathrm{Wu}$, wujingcdc@163.com; Xiaofeng Liang, liangx£@chinacdc.cn; Bernard CK Choi, bernard.Choi@utoronto.ca

\section{ABSTRACT}

Objective: To track changes of the burden and trends of childhood injury mortality among children aged 0-14 years in China from 2004 to 2011.

Design: National representative data from the Chinese Disease Surveillance Points system and Chinese Maternal and Child Mortality Surveillance system from 2004 to 2011 were used. Rates and 95\% Cls of agedstandardised mortality, as well as the proportions of injury death, were estimated.

Setting: Urban and rural China.

Participants: Children aged 0-14 years from 2004 to 2011.

Results: The proportion of injury among all deaths in children increased from $18.69 \%$ in 2004 to $21.26 \%$ in 2011. A 'V' shape change was found in the agestandardised injury mortality rate during the study period among the children aged $0-14$ years, with the age-standardised injury mortality rate decreasing from 29.71 per 100000 per year in 2004 to 24.12 in 2007 , and then increasing to 28.12 in 2011. A similar change was observed in the rural area. But the agestandardised mortality rate decreased consistently in the urban area. The rate was higher among boys than among girls. Drowning, road traffic accidents and falls were consistently the top three causes of death among children.

Conclusions: Childhood injury is an increasingly serious public health problem in China. The increasing trend of childhood injury mortality is driven by the rural areas rather than urban areas. More effective strategies and measures for injury prevention and control are needed for rural areas, boys, drowning, road traffic accidents and falls.

\section{INTRODUCTION}

Injury is the third major cause of death globally. With over 5 million people who die from injury annually, it accounts for $9.8 \%$ of global mortality. ${ }^{1}$ It also contributes significantly to global healthcare costs and society burden. Worldwide, an estimated 950000 adolescents under 18 years of age die of injury every year. ${ }^{2} 3$ In high-income countries,

\section{Strengths and limitations of this study}

High-quality national representative data were available from official government sources, and systematically analysed to provide accurate estimate of burden and trend of childhood injury mortality. Aged-standardised mortality rates and 95\% Cls were used in this study, which allowed a fair comparison of mortality rates over the years.

- The possibility of miscoding of causes of deaths could not be completely ruled out, which means the true burden of injury mortality might still be mis-estimated.

injury has been considered 'the last major plague of the young, 4 since mortality due to diseases has declined in this age group. Injury is the leading cause of death and long-term disability in children. ${ }^{56}$ More than $95 \%$ of all injury-related deaths worldwide among children and adolescents occurred in low and middle income countries. ${ }^{5}$

As a developing country, China's rapid economic growth has been accompanied by a dramatic change in lifestyle, transportation modes, work environment and other areas that cause unexpected increases in injury rates. Injury has now become the fourth leading cause of death in China. ${ }^{7}$ It is the leading cause of death among children aged 1-14 years, ${ }^{8}$ however, the burden of injury is not recognised widely in China, even among public health community and health policy decision-makers. ${ }^{9}$ Prior to this study, no official systematic investigation on childhood injury has been conducted in China, and very few studies have exclusively looked at the burden of all-cause and cause-specific injuries from infants to adolescents.

It was felt that a detailed burden and trend analysis of childhood injury mortality over the years could provide evidence on the size of the problems associated with injury, the high-risk populations and potential changes over time. This can benefit public health 
policy development and programme planning, and facilitate allocation of limited public health resources.

This study used mortality to estimate 'burden', because accurate mortality data are widely available in China. All-cause and cause-specific mortality were used to measure the burden of injury mortality. Measures that can reflect injury morbidity in children, for example, disability-adjusted life years (DALYs), were not used because national representative data for non-fatal injuries (eg, prevalence and consequences of injuries) are not available in China, as in other low and middle income countries. $^{10}$

The objective of this study was to track the burden and trend of childhood injury mortality, using Chinese national representative mortality data (all-cause and cause-specific) from the Chinese Disease Surveillance Points (DSP) system and Chinese Maternal and Child Mortality Surveillance (MCMS) system, among children aged 0-14 years in China from 2004 to 2011.

\section{METHODS}

Data

Two sources of mortality data from 2004 to 2011 were used to increase accuracy in the estimates. First, the mortality data of children 5 years of age and over were obtained from the Chinese DSP system. Second, mortality data of children under 5 years of age were obtained from the Chinese MCMS system. The DSP has highquality data for those aged 5 years and over, but it has high rates of missing data among children under 5 years of age. On the other hand, MCMS has good-quality data for children under 5 years of age.

The DSP system is sample-based and collects data, through 'disease surveillance points' located throughout China, on births, causes of death and incidence of diseases. ${ }^{11}$ It uses a multistage cluster probability sampling strategy to ensure representativeness of the general population, using samples from different geographic locations. Currently, the DSP system has 161 DSP, covering $6 \%$ of the national population of China. All deaths are reported and then re-checked according to an established protocol, and duplicate deaths are identified and eliminated as part of routine processing operations at provincial and county levels.

The mortality data from the DSP system in 2004 and 2005 were adjusted using the National Cause of Death Retrospective Survey conducted in $2006 .{ }^{12}$ The mortality data in the DSP system from 2006 to 2011 were adjusted according to the results of the Under-reporting Survey conducted every 3 years for the DSP system. $^{13}$ Under-reporting Surveys conducted in 2009 and 2012 suggested that the total under-reporting rate was $17.44 \%$ from 2006 to 2008 , and $11.63 \%$ from 2009 to $2011 .^{14}$ The total and cause-specific mortality was found to be accurate for those aged 5 years and over after adjustment with under-reporting rates. The use of both data sources (DSP and MCMS systems) is consistent with the methodology used in the 2013 Global Burden of Disease (GBD) Study. ${ }^{15}$

Previous studies have shown that the DSP system has high rates of missing data among children under 5 years of age, and even with adjustment using under-reporting rates, it was difficult to retrieve good-quality data. ${ }^{14} 16$ For this reason, and as in previous studies, ${ }^{14}{ }^{15}$ another source of mortality data (MCMS system) was used in this study to estimate the mortality rate of children under 5 years of age.

The MCMS system is a national surveillance network that monitors the mortality rates and causes of death among children under 5 years of age. The number of surveillance counties/districts increased from 116 in 1996 to 336 in 2006, the counties/districts were chosen to provide a nationally representative sample, and the methods of surveillance, reporting and quality control are consistent across MCMS sites. ${ }^{17}$ The MCMS system includes an active process of correction for possible under-reporting. ${ }^{17}$ Among children under 5 years of age, MCMS data are considered to be better than DSP data.

An important aspect of this study was to conduct rural-urban comparison. Both the DSP and MCMS systems use the same definitions: rural areas are defined as counties, and urban areas are defined as districts.

\section{Codes for causes of death}

Data for this study included demographic variables, and date, location and cause of death. Underlying causes of death were coded using a three character code from V01 to Y89 according to the intent and mechanism as specified by the International Classification of Diseases, 10th Revision (ICD-10). ${ }^{18}$ The codes identified the five major unintentional injury causes of death: motor vehicle traffic accidents (V01-V04, V06, V09-V80, V87, V89, V99), poisoning (X40-X49), falls (W00-W19), burns and fire related (X00-X09), and drowning (W65-W74), as well as other unintentional causes. In addition, the codes also identified the two major intentional injury causes of death: self-harm (X60-X84, Y87) and violence (X85-Y09, Y87.1), as well as war and other intentional causes. $^{18}$

\section{Statistics analysis}

The proportion of death (\%) caused by injury among all deaths in children aged 0-14 years was calculated for each year from 2004 to 2011. All-cause mortality includes all deaths from infectious disease, noncommunicable disease and injury, as defined by ICD-10. Age-specific proportion of injury deaths was also calculated by age subgroup $(0,1-4,5-9,10-14,1-14$ years $)$ within $0-14$ years.

All-cause and cause-specific (based on the five major unintentional and two major intentional injuries) age-standardised mortality rates (ASMR) among children aged $0-14$ years were calculated per 100000 populations per year from 2004 to 2011. Age standardisation 
was performed by the direct method with reference to 2010 Chinese national population, ${ }^{19}$ using four age subgroups $0,1-4,5-9$ and $10-14$ years as the standard population. Cause-specific injury mortality rates were also calculated by urban/rural residence and gender. Ninety-five per cent CIs for the age-standardised injury mortality rates were calculated using the 'Chiang' method. ${ }^{20} 21$

\section{RESULTS}

Trend of proportion of injury death among Chinese children aged 0-14 years from 2004 to 2011

As shown in figure 1 , the proportion of death caused by injury was the lowest among infants (age $<1$ years), and was about 5-6\%. The injury death proportion increased with age, to over $40 \%$ for children aged 1-4 years and about $60 \%$ for those aged 5-14 years.

The overall proportion of death caused by injury among children aged 0-14 years increased from $18.69 \%$ in 2004 to $21.26 \%$ in 2011, representing an increase of $13.75 \%$ over the 7 -year period. It also increased in the age subgroups, except for a slight decline of $-0.70 \%$ over the same period in the age subgroup 10-14 years. During this period, the biggest increase in proportion of injury death occurred in infants, from $4.91 \%$ in 2004 to $6.44 \%$ in 2011, representing an increase of $31.16 \%$. This was followed by age subgroups 1-4 years (an increase of $7.35 \%)$ and $5-9$ years $(3.55 \%)$ (figure 1 ).

\section{Trend of age-standardised injury mortality rates among} Chinese children aged 0-14 years from 2004 to 2011

As shown in table 1, the age-standardised injury mortality rate was significantly higher in boys than in girls, over the study period: 33.63 (95\% CI 32.23 to 35.04$)$ per 100000 and 21.81 (95\% CI 20.62 to 22.99) per 100000 , respectively, in 2011. The rate was significantly higher in the rural versus urban regions: 34.04 per 100000 and 13.83 per 100000 , respectively. Overall, the rural boys group had the highest injury mortality, followed by rural girls, urban boys and urban girls.

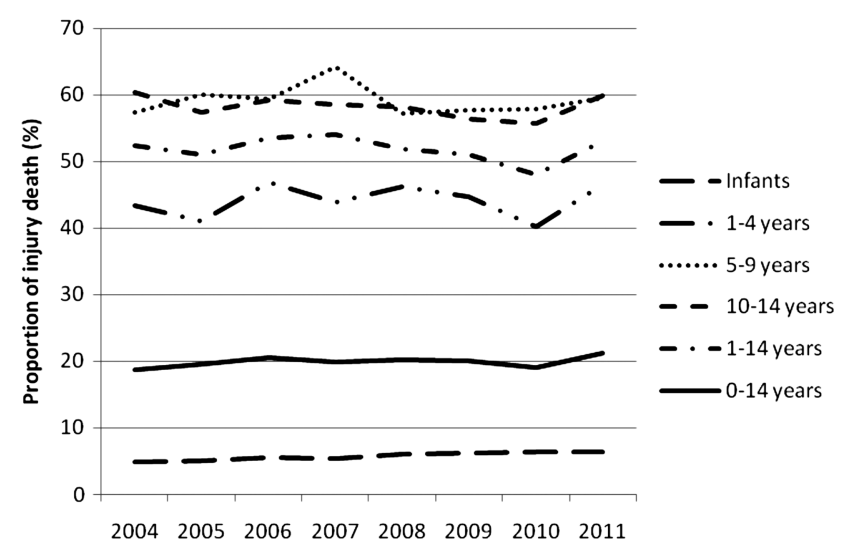

Figure 1 Proportion of injury deaths (\%) among children aged 0-14 years and by age group, China, 2004-2011.
$A^{\prime} V$ ' shape change in the age-standardised injury mortality rate was observed during the study period among the children aged $0-14$ years (table 1 ). The age-standardised injury mortality rate decreased significantly from 29.71 per 100000 per year (95\% CI 28.77 to 30.66) in 2004 to 24.12 (95\% CI 23.28 to 24.96 ) in 2007, and then increase significantly to 28.12 (95\% CI 27.96 to 29.87). Overall, there was a $5.35 \%$ decline over the 7 years, which was not statistically significant. Similar ' $V$ ' shape changes were also found among the boys, girls, rural boys, rural girls, total rural children and urban girls (table 1).The age-standardised injury mortality rate decreased significantly in 2007 , and then increased significantly, with overall changes of $-5.93 \%$, $-5.09 \%, 1.24 \%,-3.72 \%,-0.38 \%$ and $-13.89 \%$ (all were not significant). But in the urban areas, injury mortality decreased from 18.73 (95\% CI 17.36 to 20.10 ) in 2004 to 13.83 (95\% CI 12.63 to 15.03 ) in 2011, by $-26.16 \%$, which was statistical significant. A decline also appeared in the urban boys, with the mortality decreasing to 16.02 (95\% CI 14.23 to 17.82 ), by $-33.25 \%$.

Trend of age-standardised cause-specific injury mortality rates among Chinese children aged $\mathbf{0 - 1 4}$ years from 2004 to 2011

Drowning, road traffic accidents and falls have consistently been the top three causes of injury death among children aged 0-14 years (table 2). Age-standardised injury mortality rate of drowning was about 10 per 100000 per year. This was followed by road traffic accidents (about 5 deaths per 100000 per year) and falls (less than 2 per 100000 per year) (table 2).

Overall, age-standardised injury mortality rates from 2004 to 2011 increased for road traffic accidents $(14.69 \%)$, poisoning $(7.69 \%)$ and falls $(4.47 \%$; table 2$)$. The road traffic accident mortality rate increased from 5.72 per 100000 per year (95\% CI 5.31 to 6.11 ) in 2004, to 6.56 (95\% CI 6.11 to 7.02$)$ in 2011, which was statistically significant; while the overall changes of poisoning and falls in age-standardised mortality rate were not significant.

There was a slight decrease in burns $(-22.00 \%)$, drowning $(-11.00 \%)$ and two intentional injuries, namely, selfharm $(-38.82 \%)$ and violence $(-20.00 \%$; table 2$)$. Among them, only the changes in drowning and self-harm in age-standardised injury mortality rates were statistically significant. The drowning mortality rate decreased from 12.36 per 100000 per year (95\% CI 11.76 to 12.97 ) in 2004 to 11.00 (95\% CI 10.41 to 11.59 ) in 2011. The decrease in the rate of self-harm was also statistically significant. Figures 2-4 show the age-standardised injury mortality rates by gender and urban/rural residence, for drowning, road traffic accidents and falls, respectively, among children aged $0-14$ years.

\section{DISCUSSION}

To the best of our knowledge, this is the first study in China to systematically examine the burden and trend 
Table 1 Age-standardised injury mortality rates (per 100000 per year) and $95 \% \mathrm{Cl}$ among children aged 0-14 years, by urban/rural residence and gender, China, 2004-2011

\begin{tabular}{|c|c|c|c|}
\hline & Urban & Rural & Subtotal \\
\hline \multicolumn{4}{|l|}{ Total } \\
\hline 2004 & 18.73 (17.36 to 20.10$)$ & 34.17 (32.97 to 35.38 ) & 29.71 (28.77 to 30.66 ) \\
\hline 2005 & $17.39(16.08$ to 18.71$)$ & 32.88 (31.70 to 34.06$)$ & 28.41 (27.49 to 29.33$)$ \\
\hline 2006 & 16.41 (15.15 to 17.68$)$ & 32.92 (31.73 to 34.11$)$ & 27.98 (27.07 to 28.90$)$ \\
\hline 2007 & $14.63(13.46$ to 15.80$)$ & 28.27 (27.18 to 29.36$)$ & 24.12 (23.28 to 24.96$)$ \\
\hline 2008 & 13.88 (12.82 to 14.93$)$ & 36.12 (34.89 to 37.34$)$ & 28.60 (27.71 to 29.49$)$ \\
\hline 2011 & 13.83 (12.63 to 15.03$)$ & 34.04 (32.82 to 35.26$)$ & 28.12 (27.96 to 29.87$)$ \\
\hline Total $\%$ change* & -26.16 & -0.38 & -5.35 \\
\hline \multicolumn{4}{|l|}{ Boys } \\
\hline 2004 & 24.00 (21.86 to 26.13$)$ & 40.39 (38.62 to 42.15$)$ & 35.75 (34.34 to 37.16$)$ \\
\hline 2005 & 20.91 (18.94 to 22.89 ) & 38.75 (37.02 to 40.49$)$ & 33.69 (32.33 to 35.06$)$ \\
\hline 2006 & 19.46 (17.58 to 21.34$)$ & 38.90 (37.15 to 40.65$)$ & 33.19 (31.84 to 34.54$)$ \\
\hline 2010 & 17.81 (16.15 to 19.48$)$ & 38.98 (37.24 to 40.71$)$ & 32.06 (30.77 to 33.34$)$ \\
\hline 2011 & $16.02(14.23$ to 17.82$)$ & 40.89 (39.04 to 42.73$)$ & 33.63 (32.23 to 35.04$)$ \\
\hline Total $\%$ change* & -33.25 & 1.24 & -5.93 \\
\hline \multicolumn{4}{|l|}{ Girls } \\
\hline 2004 & $13.10(11.43$ to 14.78$)$ & 27.15 (25.54 to 28.75$)$ & 22.98 (21.75 to 24.22$)$ \\
\hline 2005 & $13.50(11.79$ to 15.21$)$ & 26.07 (24.51 to 27.64$)$ & 22.37 (21.16 to 23.59$)$ \\
\hline 2006 & $13.21(11.53$ to 14.88$)$ & 26.42 (24.82 to 28.02$)$ & 22.37 (21.15 to 23.60$)$ \\
\hline 2007 & 9.97 (8.54 to 11.39$)$ & 23.34 (21.85 to 24.83 ) & 19.18 (18.06 to 20.29$)$ \\
\hline 2008 & 8.37 (7.19 to 9.55$)$ & 25.63 (24.14 to 27.12$)$ & 19.76 (18.70 to 20.83$)$ \\
\hline 2009 & $13.68(12.07$ to 15.30$)$ & 26.42 (24.92 to 27.91$)$ & 22.61 (21.46 to 23.77$)$ \\
\hline 2010 & 10.26 (8.94 to 11.57$)$ & 23.17 (21.78 to 24.57$)$ & 18.96 (17.93 to 19.99$)$ \\
\hline 2011 & $11.28(9.72$ to 12.85$)$ & 26.14 (24.59 to 27.68$)$ & 21.81 (20.62 to 22.99$)$ \\
\hline
\end{tabular}

of injury mortality in children using official national data. The proportion of injury among all deaths, age-standardised injury mortality rate and the leading causes of injury death for children aged $0-14$ years over an extended period of 7 years (2004-2011) was investigated. Furthermore, the study conducted detailed subanalysis by age subgroups, urban/rural residence and gender.

Our results indicate that childhood injury is an increasingly serious public health problem in China among children aged 0-14 years, with the proportion of injury death among the total death increasing from $18.69 \%$ to $21.26 \%$ over 7 years. The overall Chinese childhood age-standardised injury mortality rate fluctuated between 24.1 and 29.7 per 100000 per year during the period from 2004 to 2011. Another important finding of our study is that injury mortality was higher in boys than in girls, and higher in rural areas than in urban areas. This is consistent with other reports in China, ${ }^{22-24}$ as well as studies conducted in developed countries, such as the USA, ${ }^{25}$ Ireland, ${ }^{26}$ Australia ${ }^{27}$ and
Norway. ${ }^{28}$ Boys in general are engaged in more high risk-taking behaviours than girls, leading to higher overall injury mortality risk.

We offer several explanations for our findings in the urban/rural difference in China. First, economic development in China in rural areas has increased, along with an increase in the use of motorised vehicles by the rural population, putting users at a higher risk of death from injuries due to road traffic accidents, falls, etc. Second, a large proportion of the rural population has migrated to work in cities (migrant workers), leaving their children in their hometowns. These children, called 'left-behind children', cannot receive enough care and adult supervision, cannot receive appropriate education on injury prevention and have few opportunities to participate in prevention programmes. These put them in a dangerous environment for injuries to occur. Also, these children cannot receive timely and proper treatments when injuries occur, due to lack of adults to take them to medical facilities. Third, the literature suggests that rural children are associated with more law 
สิษ

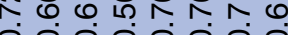
00000000 오오 오옹ㅇㅇㅇㅇㅇㅇㅜ

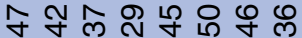
- óóó

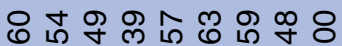
00000000 वे

ชิธ 1000000 오오 오오오 오오 오

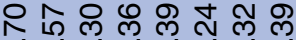

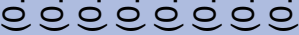

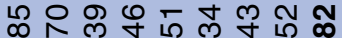
०0 00000000

Кิธิ์

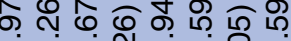

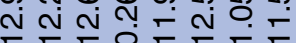
웅ㅇㅇㅇㅇㅇㅇㅇㅇㅇ

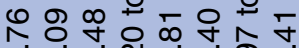

violations and high-risk behaviours, such as drinking and driving, driving without a license, and violating pedestrian and bicycle traffic rules, than their urban counterparts. ${ }^{29}$ Additionally, low household income has been shown to be related with an increased risk of childhood unintentional injury mortality. ${ }^{30}$ All these factors together contribute to a higher overall injury mortality in the rural population compared to urban.

Another important finding in our study is the ' $\mathrm{V}$ ' shape trend in the age-standardised injury mortality rates observed from 2004 to 2011 in the total population of children aged 0-14 years, especially in rural areas. There was a decline in injury mortality during the initial years of the study period, followed by an increase. This was observed among boys as well as girls in the rural area. This phenomenon is different from that observed in Canada from 1979 to 2002, during which annual injury mortality rates decreased dramatically from 23.8 to 7.2 per 100000 populations. ${ }^{6}$ In our study, only the urban area showed a consistent decrease throughout the 7-year period (2004-2011). This is a welcome trend for the urban area, as a rising trend in injury mortality has been reported for China in the urban area before 2004$2005 .{ }^{31}$ The decline in the mortality rates in urban areas may result from the many intervention measures taken over the years, including health education, health promotion or intervention programmes. Examples include the government of China's Safety Community Campaign since 2006, which was initiated by the $\mathrm{WHO},{ }^{32}$ as well as the Safe Kids Campaign, which focuses on the prevention of injury among children aged 1-14 years. ${ }^{33}$ Second, safety legislations and government regulations have been issued and implemented, including the Road Traffic Safety Law, which, since 2004, has placed regulations on road traffic safety, ${ }^{34}$ and more regulations on drunk-driving since 2011. In addition, regulations on water hazards, minimum age for alcoholic beverages, and product modification, have been introduced. ${ }^{35}$

We have some possible explanations for the rural increase in the latter part of the study period. With urbanisation and economic development in the rural area, rural children face new challenges that they were rarely exposed to, for example, more motor traffic and increased drunk driving. Few measures and programmes to prevent the occurrence of injury are available in the rural area. As a result, the increased risk of injury brought about by rapid socioeconomic development in the rural areas cannot be dealt with as efficiently as in the urban area, leading to increased injury mortality in the rural area in the latter years. Thus the gap in injury mortality between rural and urban areas has widened over time.

Another interesting observation was that the age-standardised injury mortality rate of urban boys decreased (by $-33.25 \%$ ), which is more of a decrease than that of urban girls (by $-13.89 \%$ ), from 2004 to 2011. We postulate, for reasons yet to be determined, that boys are more likely than girls to respond positively 


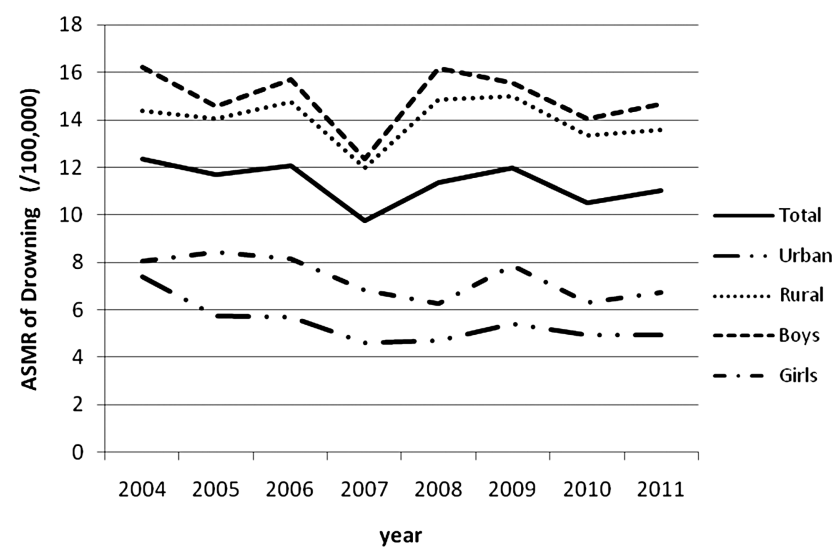

Figure 2 Age-standardised injury mortality rates (per 100000 per year) for drowning, by gender and urban/ rural residence, among children aged 0-14 years, China, 2004-2011. ASMR, age standardised mortality rate.

to injury prevention measures, and/or to resist risky injury behaviours. It is possible that boys may receive more attention and protection than girls by the society because of the traditional Chinese ideology of a male dominant society.

Our results show that drowning is the leading cause of injury death in children aged $0-14$ years, which is consistent with another study conducted in a local county in China. ${ }^{36}$ However, road traffic is the leading cause of injury death in developed countries, for example, the USA. $^{37}$ Injury mortality from drowning has been decreasing in Chinese children from 2004 to 2011 (by $-11.00 \%)$, probably due to multifaceted intervention measures, such as the installation of barriers or fencing, more adult supervision, and educational and intervention programmes, for example, the SwimSafe programme conducted in Asian countries including China, which focused on teaching survival swimming skills. ${ }^{38}$ Road traffic accidents are the second major cause of injury death among Chinese children. Road traffic injury has become a serious public health problem in

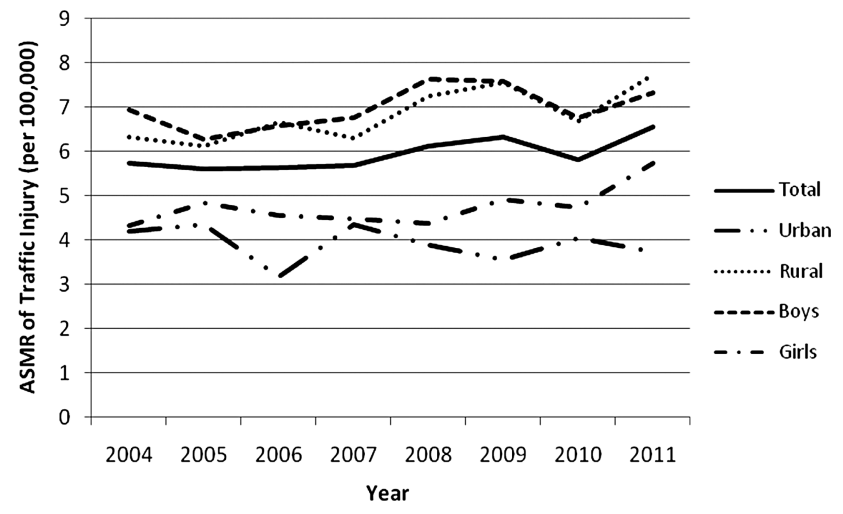

Figure 3 Age-standardised injury mortality rates (per 100000 per year) for traffic injury, by gender and urban/ rural residence, among children aged 0-14 years, China, 2004-2011. ASMR, age standardised mortality rate.

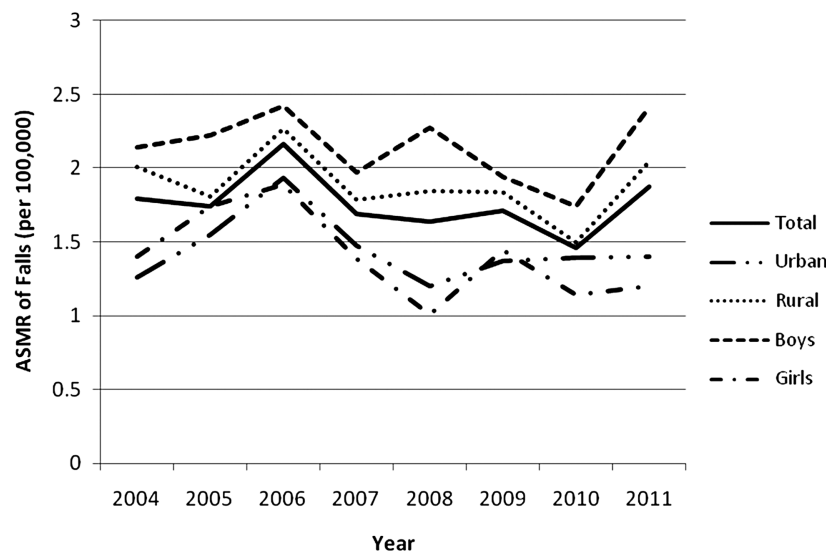

Figure 4 Age-standardised injury mortality rates (per 100000 per year) for falls, by gender and urban/rural residence, among children aged 0-14 years, China, 2004-2011. ASMR, age standardised mortality rate.

China because of the rapid growth in road construction and the rising number of motorised vehicles. ${ }^{9}$ From our study, the mortality rate of road traffic increased from 2004 to 2011. Several factors, such as careless driving, especially in rural areas, vehicle overloading, drunk driving, as well as limited access to emergency medical treatment, could contribute to this increasing risk. Fall-related mortality increased from 2004 to 2011, so some effective strategies and measures, such as creating mass media messages directed at parents and health workers, using stair gates and guard rails, legislating for window guards, establishing playground standards for the height of equipment and redesigning nursery furniture, as well as creating more community programmes, should be implemented to prevent and control fallrelated mortality in China.

Our study has several strengths and limitations. Data were obtained from two data sources, including the official Chinese DSP system (for children 5 years old or above) and the Chinese MCMS system (for children aged under 5 years). This approach allows the bestquality data to be used for the estimation of child injury mortality rates. It has been shown that the estimated mortality rate for 2008 from the MCMS system is about 18.2 per 1000 children under 5 years of age, which is very close to the United Nations' independent projection for China for 2008. ${ }^{17}$ Advanced statistical methods, including ASMRs and their 95\% CIs were used in this study, which allow for a fair comparison of mortality rates over the years. However, inevitably, our study also has several limitations. First, the DSP and MCMS systems are all based on surveillance points; even the use of advanced sampling methods cannot fully guarantee representativeness of the data. Second, we have the average under-reporting rate for every 3 years, but no yearly under-reporting rate. So it was not possible for this study to evaluate the deterioration of data quality over the years, which may result in a potential bias causing observed fluctuations in the secular trends. Third, 
despite multiple methods to assure accuracy, the possibility of miscoding of deaths by cause cannot be completely ruled out. So the true burden of injury mortality may still be mis-estimated.

In conclusion, a ' $\mathrm{V}$ ' shape change was observed in the injury mortality rate (a decrease from 2004 to 2007 followed by a subsequent increase) and in the rural area among children aged 0-14 years in China, from 2004 to 2011; on the other hand, the rate decreased consistently in urban areas in the same period, which meant the increasing trend in China is driven by rural areas rather than urban areas. Moreover, boys had a consistently higher injury mortality rate than girls. Drowning, road traffic and falls have consistently been the top three causes of injury death.

Our finding has important implications for policy development. For example, since rural areas have been identified as problem areas of injury mortality, further investigation should be conducted to identify the risk factors that contribute to the increasing mortality rate in these areas. Once the high-risk groups are identified, invention programmes can be developed and implemented on injury prevention in rural areas. There are effective strategies and measures for injury prevention and control for drowning, road traffic accidents and falls, for example, fencing around swimming pools, ensuring immediate medical treatment, using appropriate child restraints and seat-belts, and implementing community programmes such as 'Children Can't Fly'. ${ }^{39}$

Contributors $Z Y$ conducted data analysis, drafted and revised the manuscript. $\mathrm{JW}$ and BCKC helped conduct data analysis, and critically revised the manuscript. JL and AWPP helped analyse and clean the data, and also help revise the manuscript. XL designed the study and directed its implementation, and reviewed and revised this manuscript critically.

Funding This research received no specific grant from any funding agency in the public, commercial or not-for-profit sectors.

Competing interests None declared.

Provenance and peer review Not commissioned; externally peer reviewed.

Data sharing statement No additional data are available.

Open Access This is an Open Access article distributed in accordance with the Creative Commons Attribution Non Commercial (CC BY-NC 4.0) license, which permits others to distribute, remix, adapt, build upon this work noncommercially, and license their derivative works on different terms, provided the original work is properly cited and the use is non-commercial. See: http:// creativecommons.org/licenses/by-nc/4.0/

\section{REFERENCES}

1. World Health Organization. Violence, injuries and disability biennial report, 2006-2007. Geneva: World Health Organization, 2008.

2. World Health Organization. The global burden of disease: 2004 update. Geneva: World Health Organization, 2008.

3. Peden M, Oyegbite K, Ozanne-Smith J, et al. World report on child injury prevention. Geneva: World Health Organization, 2008.

4. Committee on Trauma Research, Commission on Life Sciences, National Research Council, Institute of Medicine. Injury in America: a continuing public health problem. Washington DC: National Academy Press, 1985
5. World Health Organization. Child and adolescent injury prevention: a WHO plan of action 2006-2015. Geneva: World Health Organization, 2006.

6. Pan SY, Ugnat AM, Semenciw R, et al. Trends in childhood injury mortality in Canada, 1979-2002. Inj Prev 2006;12:155-60.

7. Wang LJ, Hu N, Wan X, et al. Status and trend of injury deaths among Chinese population, 1991-2005. Zhonghua Yu Fang Yi Xue Za Zhi 2010;44:309-13.

8. Ministry of Health of China. China's health statistics yearbook 2011. Beijing: Peking Union Medical University Press, 2011.

9. Wang SY, Li YH, Chi GB, et al. Injury-related fatalities in China: an under-recognised public-health problem. Lancet 2008;372:1765-73.

10. Chandran A, Hyder AA, Peek-Asa C. The global burden of unintentional injuries and an agenda for progress. Epidemiol Rev 2010;32:110-20.

11. Yang G, Hu J, Rao KQ, et al. Mortality registration and surveillance in China: History, current situation and challenges. Popul Health Metr 2005;3:3

12. Yang G, Kong L, Zhao W, et al. Emergence of chronic non-communicable diseases in China. Lancet 2008;372:1697-705.

13. Ministry of Health, Chinese Academy of Prevention Medicine Reports series on Chinese disease surveillance (Report no. 6): 1995 annual report on Chinese disease surveillance. Beijing: People's Medical Publishing House, 1997.

14. Liu MB, Wang W, Zhou MG. Trend analysis on the mortality of cardiovascular diseases from 2004 to 2010 in China. Zhonghua Liu Xing Bing Xue Za Zhi 2013;34:985-8.

15. GBD 2013 Mortality and Causes of Death Collaborators. Global, regional and national age-sex specific all-cause and cause-specific mortality for 240 causes of death, 1990-2013: a systematic analysis for the Global Burden of Disease Study 2013. Lancet 2015;385:117-71.

16. Ma S, Li Q, Zhou M, et al. Road traffic injury in China: a review of national data sources. Traffic Inj Prev 2012;13(Suppl 1):57-63.

17. Rudan I, Chan KY, Zhang JS, et al. Cause of deaths in children younger than 5 years in china in 2008. Lancet 2010;375:1083-9.

18. World Health Organization. International statistical classification of disease and health related problems. 10th revision. Geneva, Switzerland: World Health Organization, 1993.

19. Doll R, Smith PG. Comparison between registries: age standardised rates. In: Waterhouse JAH, Muir CS, Shanmugaratnam K, et al. eds. Cancer incidence in five continents. Vol IV. Lyons, NY: IARC Scientific Publication, 1982:671-5.

20. Chiang CL. Standard error of the age-adjusted death rate. In: U.S. Department of Health, Education, and Welfare, eds. Vital statistics special reports. Vol 47. Washington DC: Department of Health, Education, and Welfare, 1961:271-85.

21. Curtin LR, Klein RJ. Direct standardization (age-adjusted death rates). Healthy people 2000, statistical notes, number 6 revised. Hyattsville, MD: Centers for Disease Control and Prevention, National Center for Health Statistics, U.S Department of Health and Human Services, 1995.

22. Zhang L, Li Z, Li X, et al. Study on the trend and disease burden of injury deaths in Chinese population, 2004-2010. PLOS ONE 2014;9: e85319.

23. Hu G, Baker SP, Baker TD. Urban-rural disparities in injury mortality in China, 2006. J Rural Health 2010;26:73-7.

24. Jiang G, Choi BC, Wang D, et al. Leading causes of death from injury and poisoning by age, gender and urban/rural areas in Tianjin, China 1999-2006. Injury 2011;42:501-6.

25. Sorenson SB. Gender disparities in injury mortality: consistent, persistent, and larger than you'd think. Am J Public Health 2011;101 (Suppl 1):353-8.

26. Boland M, Staines A, Fitzpatrick $P$, et al. Urban-rural variation in mortality and hospital admission rates for unintentional injury in Ireland. Inj Prev 2005;11:38-42.

27. Mitchell RJ, Chong S. Comparison of injury-related hospitalized morbidity and mortality in urban and rural areas in Australia. Rural Remote Health 2010;10:1326.

28. Bakke HK, Hansen IS, Bendixen AB, et al. Fatal injury as a function of rurality-a tale of two Norwegian counties. Scand J Trauma Resusc Emerg Med 2013;21:14.

29. Liu N, Yang GH, Ma JM, et al. Injury associated health risk factors in Chinese people, in 2002. Zhonghua Liu Xing Bing Xue Za Zhi 2005;26:746-50.

30. D'Souza AJ, Blakely TA, Woodward A. The effect of eradicating poverty on childhood unintentional injury mortality in New Zealand: a cohort study with counterfactual modelling. J Epidemiol Community Health 2008;62:899-904. 
31. Zhao J, Tu EJ, McMurray C, et al. Rising mortality from injury in urban China: demographic burden, underlying causes and policy implications. Bull World Health Organ 2012;90:461-7.

32. WHO Collaborating Centre on Community Safety Promotion. Safe communities. Stockholm: Karolinska Institutet, Department of Public Health Sciences, Division of Social Medicine, 2012. http://www.phs. ki.se/csp/index_en.htm (accessed 28 Mar 2012).

33. Ferguson RW, Yang M, Walker L, et al. Safe roads/safe kids: global road safety for children. Washington DC: Safe Kids Worldwide, 2014.

34. World Bank. China road traffic safety: the achievements, the challenges, and the way ahead. Washington: World Bank, China and Mongolia Sustainable Unit, 2008.
35. Li L, Scherpbier R, Wu J, et al. Legislation coverage for child injury prevention in China. Bull World Health Organ 2015;93:169-75.

36. Wang $\mathrm{XH}$, Chen $\mathrm{ZX}, \mathrm{Xu} \mathrm{ZL}$. Death causes in children aged $<15$ years in Jinhua, Zhejiang, 2006-2012. Disease Surveillance 2014;29:665-8.

37. Johnston BD, Ebel BE. Child injury control: trends, themes, and controversies. Acad Pediatr 2013;13:499-507.

38. Http://swimsafe.org/SwimSafe. The Alliance for Safe Children. http://swimsafe.org/about-swimsafe/swimsafe-history/ (accessed 15 May 2012).

39. Spiegel CN, Lindaman FC. Children can't fly: a program to prevent childhood morbidity and mortality from window falls. Am J Public Health 1977;67:1143-7. 